\title{
ASSESSMENT OF GPS/GLONASS POINT POSITIONING IN BRAZILIAN REGIONS WITH DISTINCT IONOSPHERIC BEHAVIOR
}

\author{
Gabriel Oliveira Jerez ${ }^{1}$ - ORCID:0000-0001-6893-2144
}

Daniele Barroca Marra Alves ${ }^{2}$ - ORCID: 0000-0002-9033-8499

${ }^{1}$ Universidade Estadual Paulista - UNESP, Faculdade de Ciências e Tecnologia, Programa de Pós-Graduação em Ciências Cartográficas, Presidente Prudente - São Paulo, Brasil.

E-mail: gabriel.jerez@unesp.br

${ }^{2}$ Universidade Estadual Paulista - UNESP, Faculdade de Ciências e Tecnologia, Departamento de Cartografia, Presidente Prudente - São Paulo, Brasil.

E-mail: daniele.barroca@unesp.br

Received in $26^{\text {th }}$ February 2020

Accepted in $21^{\text {st }}$ May 2020

\begin{abstract}
:
Nowadays GPS (Global Positioning System) and GLONASS (GLObal NAvigation Satellite System) are the main systems of GNSS (Global Navigation Satellite Systems), also composed by Galileo and BeiDou. After a long period of degradation, GLONASS was modernized, and its constellation was reestablished in 2011. Considering this new scenario, with GPS and GLONASS full constellations, the interest in the combined use of both systems was renewed. Besides the constellations used, other factors are related to the positioning quality, for instance the ionospheric influence. Several studies have been performed aiming to assess GPS positioning quality as well as the ionospheric influence on it, but concerning GLONASS, there are still several possibilities of investigation. In this context, this research aimed to assess the GPS/GLONASS data point positioning performance considering Brazilian regions with different ionospheric behavior during periods of low and high ionospheric activity. Spatial and time ionospheric influence in the positioning performance were observed. Considering all configurations tested with 30-minute data, the use of GPS/GLONASS data provided better results in $97.35 \%$ of the cases when compared to autonomous GPS, the mean improvement was about $60 \mathrm{~cm}$, which corresponds to $30 \%$.
\end{abstract}

Keywords: Positioning; GPS/GLONASS; lonosphere.

How to cite this article: JEREZ, G.O.; ALVEZ, D. B. M. Assessment of GPS/glonass point positioning in brazilian regions with distinct ionospheric behavior. Bulletin of Geodetic Sciences. 26(2): e2020010, 2020 


\section{Introduction}

Global Navigation Satellite Systems (GNSS) are composed by GPS (Global Positioning System), GLONASS (GLObal NAvigation Satellite System), Galileo and BeiDou. GPS and GLONASS were the pioneer systems, reaching full constellation in 1995. After a long degradation period, GLONASS passed thru a modernization and reestablishment program. In 2011, the system reached full constellation again and thus the interest by the combined use of GPS and GLONASS data for positioning was renewed. The availability of more GNSS constellations is important due to the number of visible satellites, which can increase the number of observables and improve the geometry of the satellites (Feairheller and Clark, 2006; Hofmann-Wellenhof, Lichtenegger and Wasle 2008; Revnivykh et al., 2017).

In order to assess the quality of the GNSS positioning, many issues can be considered, for example, the type and number of observables used, constellations available, methods applied and the errors that can affect the GNSS signal. The transmitted signal can be influenced by several sources of errors on the path to the receiver. One of the main sources is the ionosphere, a layer of the atmosphere with height between 50 and $1000 \mathrm{~km}$. The ionospheric influence is proportional to the Total Electron Content (TEC), which varies in time and space. Differences in the distribution of electrons in the ionosphere are related to many factors, such as the position on the surface of the Earth, the geomagnetic field activity, season of the year, solar ionization flow and sunspot cycles. Seasonal variations are caused by changes in the electron density due to changes of the sun's zenith angle and changes in the neutral atmosphere. Long period cycles are intervals of approximately 11 years, associated with sunspots, the peak of the last solar cycle was between 2013 and 2014 (McNamara, 1991).

Considering space variations, the electron density is higher in the equatorial region. In these locations the ionospheric effect is related, among other factors, to the Equatorial lonization Anomaly (EIA), with higher intensity at the local anomaly peak (approximate geomagnetic latitude of $15^{\circ}$ ) (McNamara, 1991). It is worthwhile to highlight that most part of the Brazilian territory is located in the equatorial region and it is influenced by the EIA. The EIA is generated in the magnetic equator, the equatorial ionosphere plasma is lifted in daylight and intensified after sunset ( $21 \mathrm{~h}$ LT - Local Time). The plasma diffuses at low latitudes due to pressure gradients and gravity action (a phenomenon known as the fountain effect) (de Rezende et al., 2007; Moraes et al., 2018). The anomalies of ionosphere can cause rapid variations in amplitude and phase of GNSS signals, an effect known as ionospheric scintillation (Klobuchar, 1996; Conker et al., 2003).

Many efforts have been made to improve positioning techniques integrating GPS and GLONASS data. Cai and Gao (2013a) presented a model for Precise Point Positioning (PPP) using GLONASS data with an algorithm developed to compute the frequency channel number using code and phase observations. The same authors also developed a model for integrating GPS and GLONASS data (Cai and Gao, 2013b). Li and Zhang (2014) adopted a single-difference model to combine GPS/GLONASS dual-frequency carrier phase measurements, considering the highest GPS satellite as reference. Silva and Marques (2016) investigated the adjustment mathematical model for GPS/GLONASS PPP and performed a study of a time series with daily solutions, considering Brazilian stations. Geng and Shi (2017) carried out a strategy for simultaneous GPS and GLONASS dual-frequency PPP ambiguity resolution.

Efforts have also been made concerning the assessment of GLONASS data performance on the positioning. Pinto, Camargo and Monico (2013) investigated the influence of the use of GLONASS data for relative positioning in the georeferencing of rural properties in Brazil. Alkan et al. (2015) compared the use of GPS and GPS/GLONASS for positioning of urban areas of Turkey. Jerez, Alves and Souza (2015) performed a study of the use of GPS/GLONASS data, collected by a Brazilian station, with different data collection times and two positioning methods, considering the influence of ionospheric scintillation. Cai et al. (2015) presented a multi-constellation study, comparing different configurations of the four GNSS systems, using five stations located in China, Australia and Japan.

In this paper, we present an assessment of the GPS/GLONASS point positioning in the Brazilian territory considering the ionospheric influence. In this intend, data of six GNSS stations in three distinct regions were used 
also considering two periods of the year, with lower and higher ionospheric activity. It was also considered two data sets, with single and dual-frequency data, and two intervals of data collection.

\section{Method}

In this paper, we used data of six GNSS stations from RBMC (Brazilian Network for Continuous Monitoring). The stations were selected in order to represent three Brazilian regions with different ionospheric behavior. Stations CEFT and PBJP, representing a region nearest the Geomagnetic Equator, SPDR and PPTE, representing a region affected by the fountain effect, and stations SCFL and POAL, representing a region with lower ionospheric activity. Figure 1 presents the locations of the RBMC stations selected.

Data from RBMC stations were applied to point positioning processing (static mode) using the online software CSRSPPP (Canadian Spatial Reference System - Precise Point Positioning) developed by NRCan (Natural Resources Canada). The periods considered were June (low ionospheric influence) and October (high ionospheric activity). These characteristics are due to the seasonal condition and zenithal angle of the Sun related to the region of the stations used in this study. The selection of the year (2014) was intended to take into consideration the last eleven-year solar cycle (cycle 24), with peak between 2013 and 2014. Files with 30-minute and 04-hour of data collection, starting at OOh UT - Universal Time (21h Local Time) were used. The selection of the collection starting time aimed to consider the influence of ionospheric scintillation. We used files with single and dual-frequency data, collected using $10^{\circ}$ elevation mask, 15 seconds sample rate, with GPS or GPS/GLONASS data. Figure 2 presents the processing configurations used for each station, considering that for each position were processed observations files with GPS and GPS/GLONASS data, from June and October, considering 30 minutes and 04 hours of data collection and single and dual-frequency data. In the software used for data processing, Davis and Hopfield models are used for the estimation of hydrostatic and wet components of the neutral atmosphere, respectively. L1 data processing is performed using pseudorange and IONEX files for ionospheric modeling. L1/L2 data processing uses phase and pseudorange and a linear combination (ion-free) to mitigate the ionospheric effect.

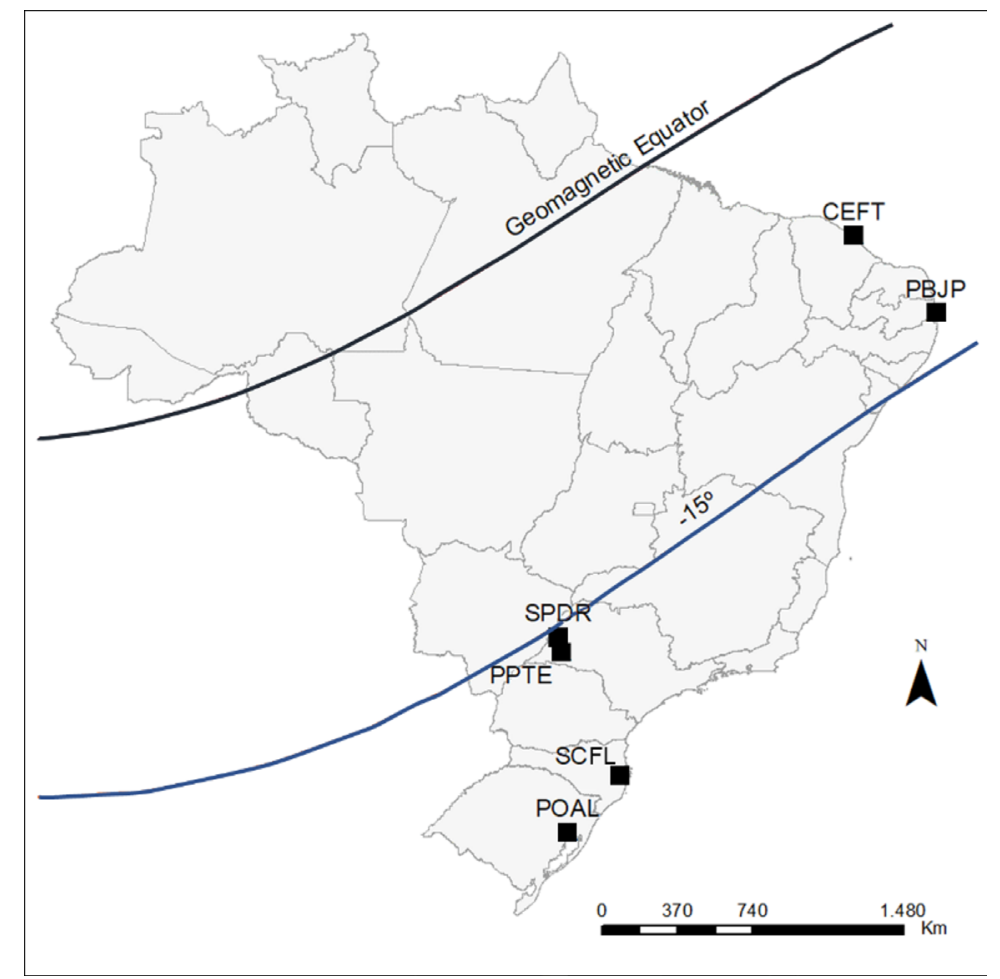

Figure 1: Locations of the RBMC selected stations. 


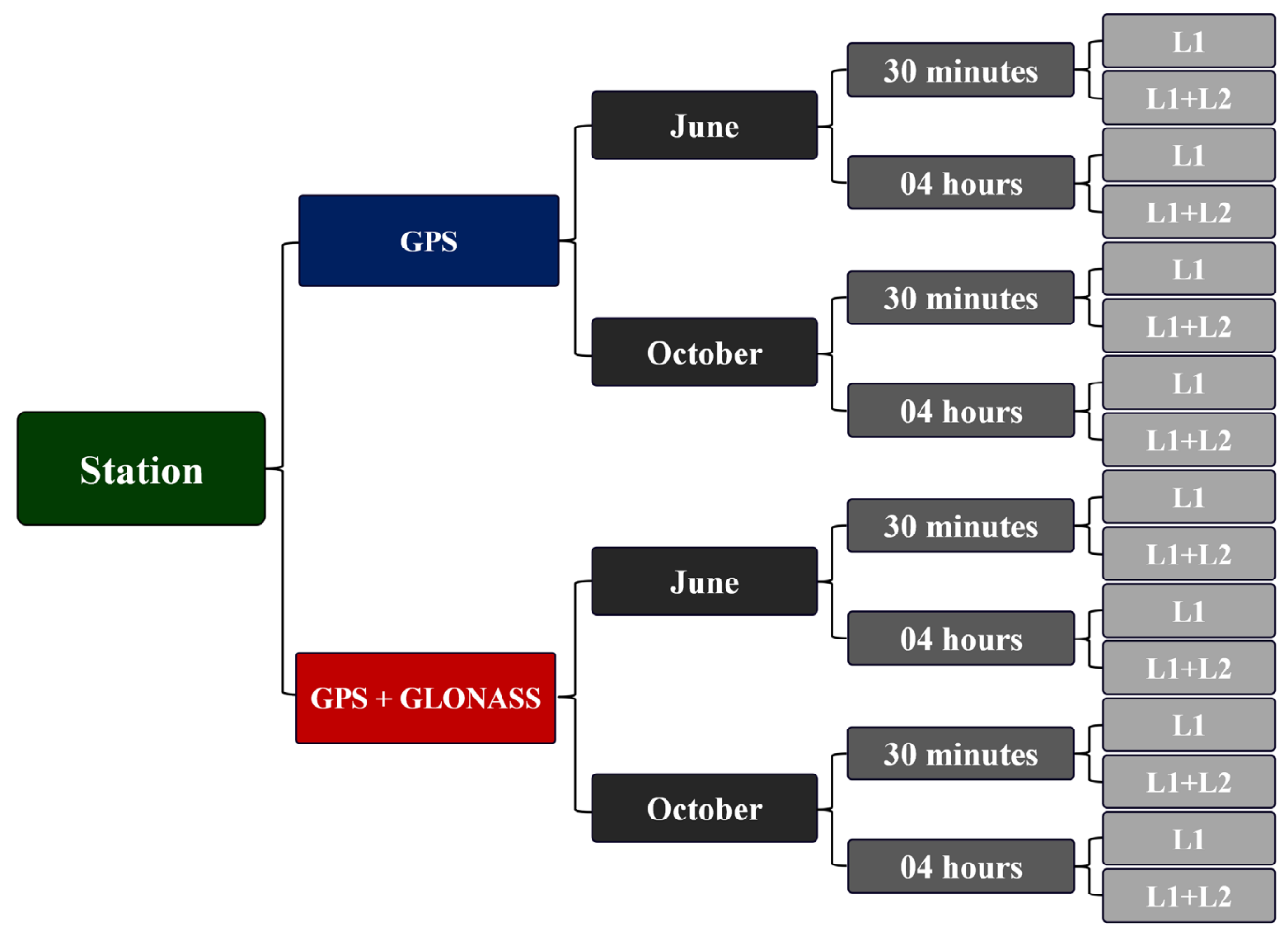

Figure 2: Processing configurations used for each station.

The positioning results were compared with the official station coordinates (provided by the Brazilian Institute of Geography and Statistics), transformed to the same reference frame and updated to the epoch of the campaign. Using these discrepancies and the standard deviation from the processing, the mean squared errors (MSE) were obtained.

\section{Results and Discussions}

In this section, we present MSE values obtained with 30-minute data, according to the station considered. The first region presented is the nearest of Geomagnetic Equator, represented by stations CEFT (Figure 3) and PBJP (Figure 4). Graph a) presents results of L1 data and graph b) L1/L2 data, both from June; Graph c) presents results of L1 data and graph d) L1/L2 data, both from October. Results from GPS constellation are presented in blue and GPS/GLONASS in red. We emphasize that days with lack of data were suppressed, only days with full data sets were retained in the analysis.

The influence of the use of single or dual-frequency data in the positioning can be noticed in all results. There is a different order of magnitude of error when using L1 data (Graphs a and c) compared with L1/L2 data (Graphs b and d), reflecting on the differences in the graphs rating scales. One explanation for that behavior is the use of the linear combination (ion-free) of observables of dual-frequency, which mitigates the ionospheric first order influence.

It is also possible to identify more irregular behavior in results with October data (Graphs c and d), as mentioned before, a period characterized by more intense ionospheric activity. That difference is even bigger in the PBJP station, located nearest $-15^{\circ}$ latitude (region affected by the fountain effect) than CEFT (Figure 1). Concerning the GPS/GLONASS data, CEFT station presented better results in almost all days considered (96,6\%) when combined data were used. Only four days using L1 data from June (Graph a) presented smaller MSE with just GPS data. PBJP presented similar behavior with just one configuration with better results in four days using GPS-only data, it was also with L1 data, but in this case with data from October (Graph c). 
a)

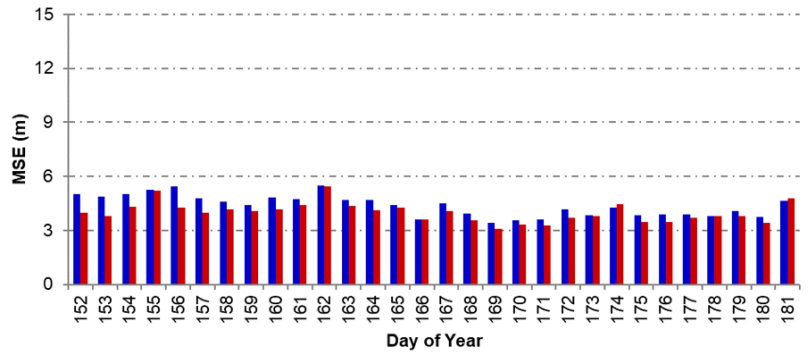

c)

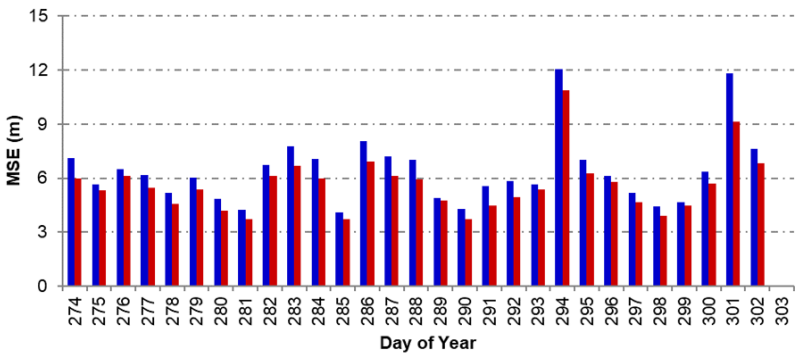

b)

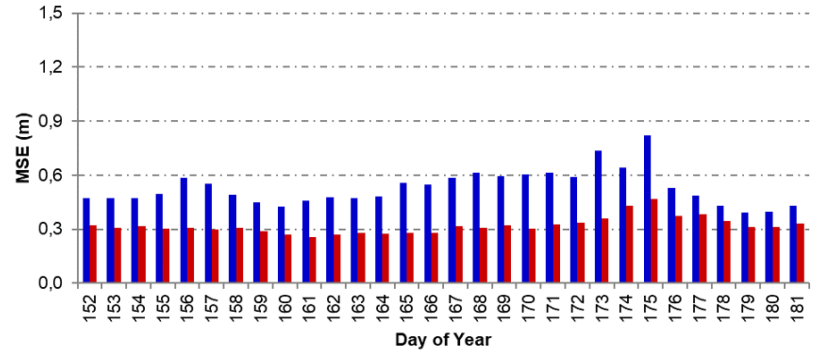

d)

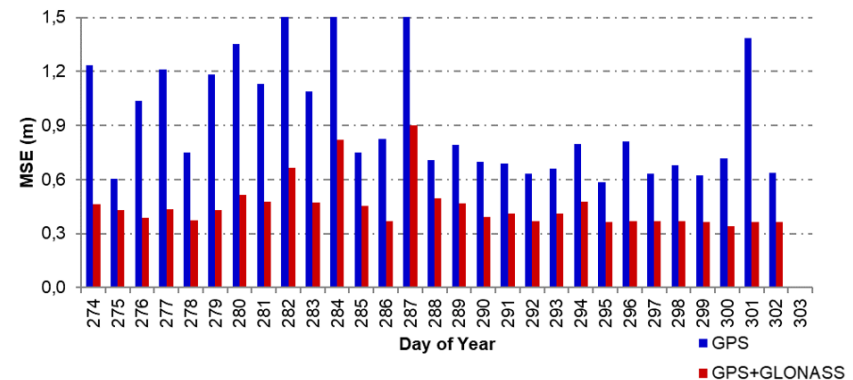

Figure 3: MSE results for PPP processing considering CEFT station with 30-minute data. a) L1 data collected in June; b) L1/L2 data collected in for June; c) L1 data collected in for October; d) L1/L2 data collected in for October.

a)

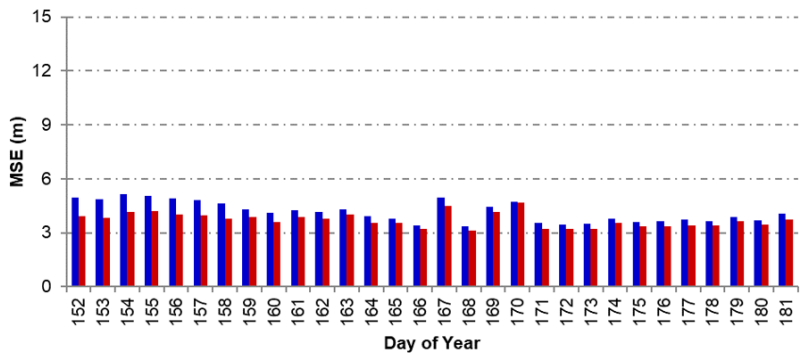

c)

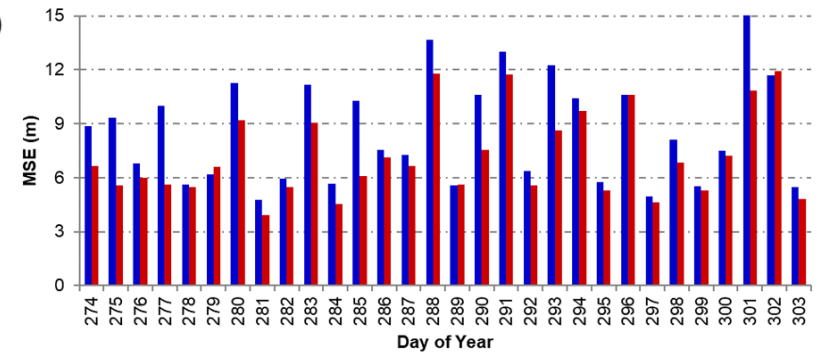

b)

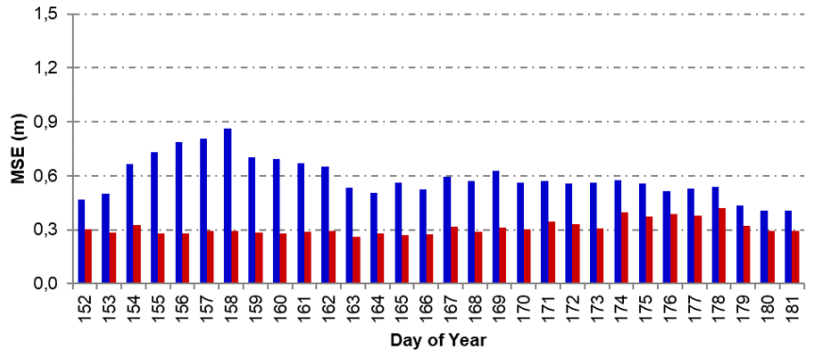

d)

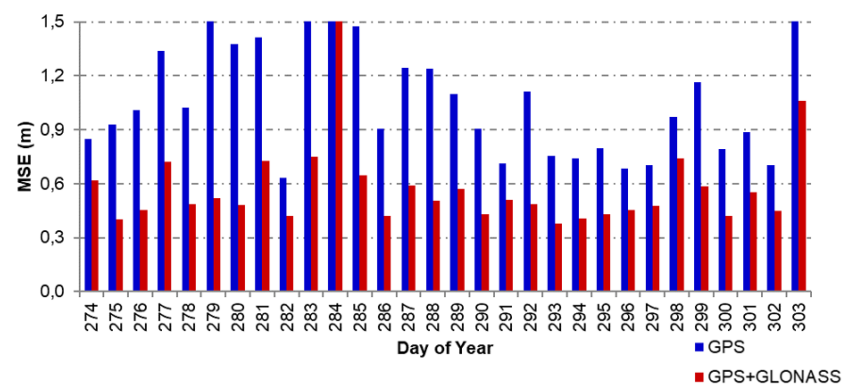

Figure 4: MSE results for PPP processing considering PBJP station with 30-minute data. a) L1 data collected in June; b) L1/L2 data collected in for June; c) L1 data collected in for October; d) L1/L2 data collected in for October.

The second region considered is affected by the fountain effect, represented by stations SPDR (Figure 5) and PPTE (Figure 6). The results of L1 data of SPDR and PPTE stations presented similarity with those from CEFT (Figure 3) and PBJP (Figure 4), the similarity was also observed concerning the order of magnitude of the errors. On the other hand, with L1/L2 data, it is noted a significant increase in the positioning error, mainly with October data. It is also more evident the improvement in the positioning performance, by adding GLONASS to GPS observables. Results from SPDR presented improvement in almost all the days analyzed $(97,5 \%)$ by using GPS/GLONASS data, except by three days of L1 data from October. PPTE data also obtained better results for almost all days considered $(96,6 \%)$ by using both constellations, except for four days: three days with L1 data (one from June and two from October) and one with L1/L2 data from October. It is also worthwhile to highlight that this region is one of the most affected by the ionospheric activity. 
a)

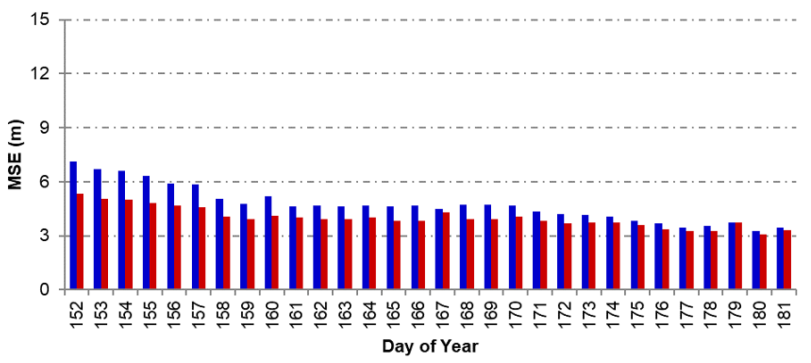

c)

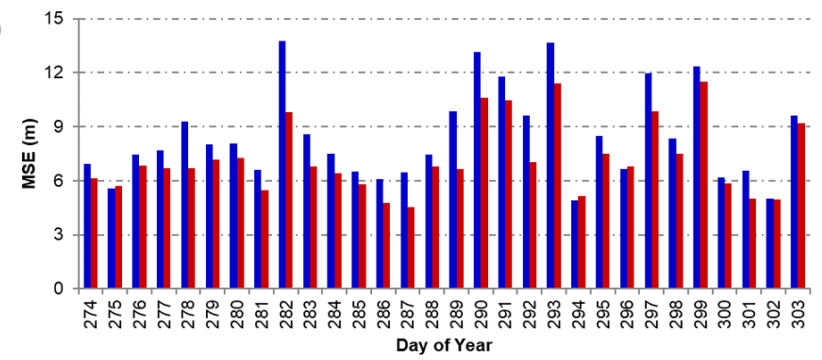

b)

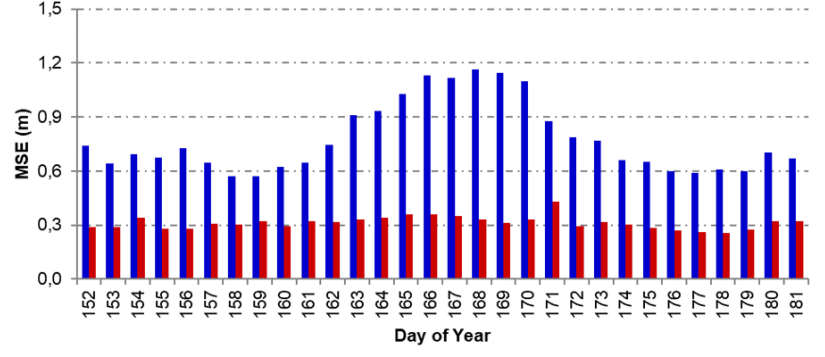

d)

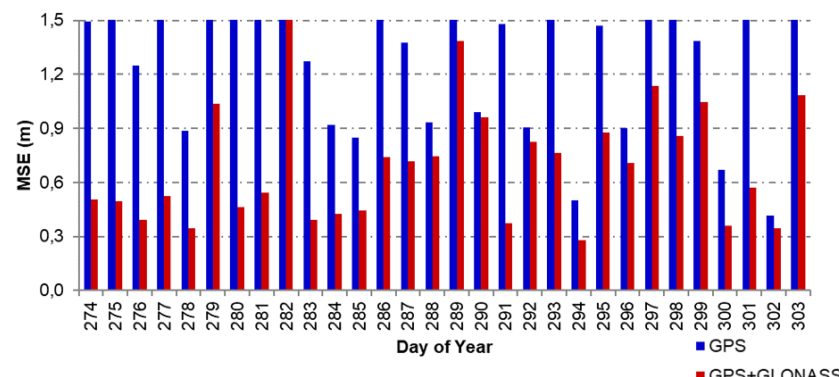

Figure 5: MSE results for PPP processing considering SPDR station with 30-minute data. a) L1 data collected in June;

b) L1/L2 data collected in for June; c) L1 data collected in for October; d) L1/L2 data collected in for October.

a)

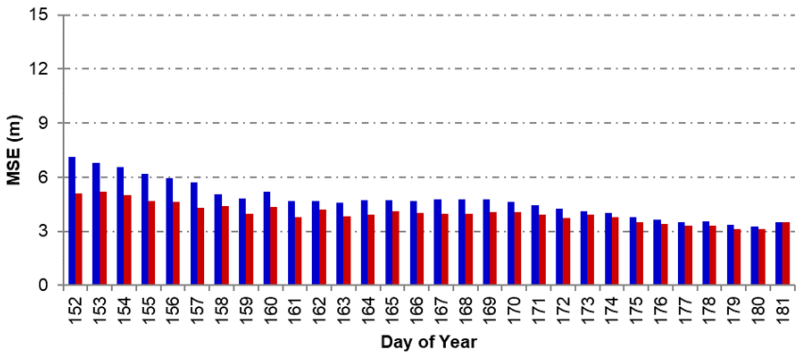

c)

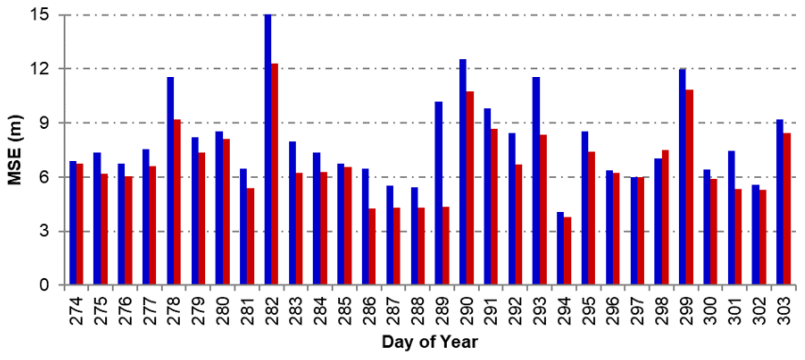

b)

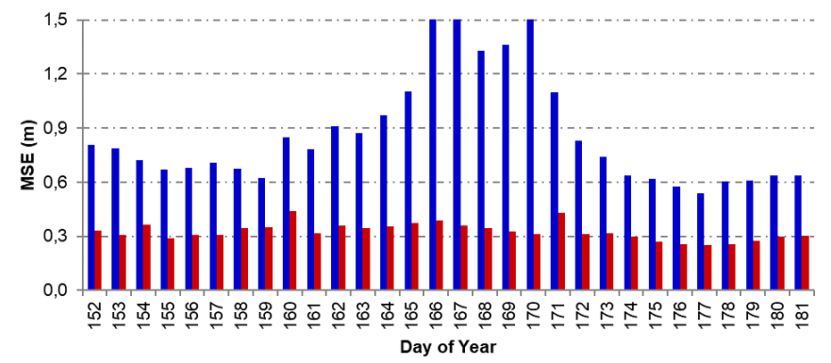

d)

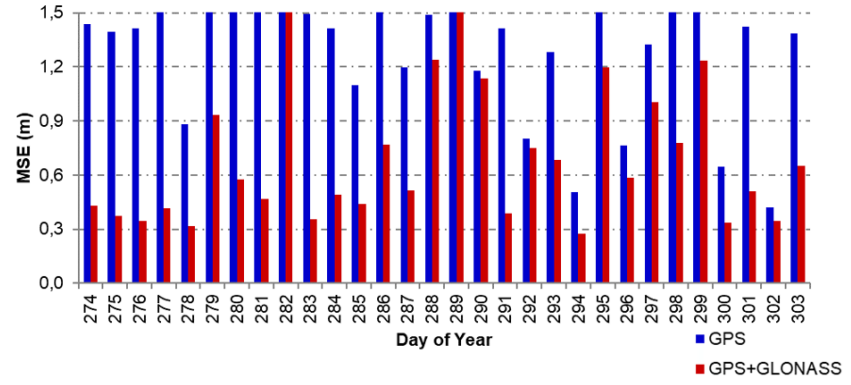

Figure 6: MSE results for PPP processing considering PPTE station with 30-minute data. a) L1 data collected in June; b) L1/L2 data collected in for June; c) L1 data collected in for October; d) L1/L2 data collected in for October.

The region with lower ionospheric activity is represented by stations SCFL (Figure 7) and POAL (Figure 8). Stations in this region commonly present least variable results considering seasonal variations. These results also obtained the smaller errors taking into account the three regions analyzed and, once again, almost all the days considered (98,3\%) presented better results with GPS/GLONASS data. The exceptions were three days of SCFL station, with L1 data from October and one day of POAL station, also with L1 data from October. 
a)

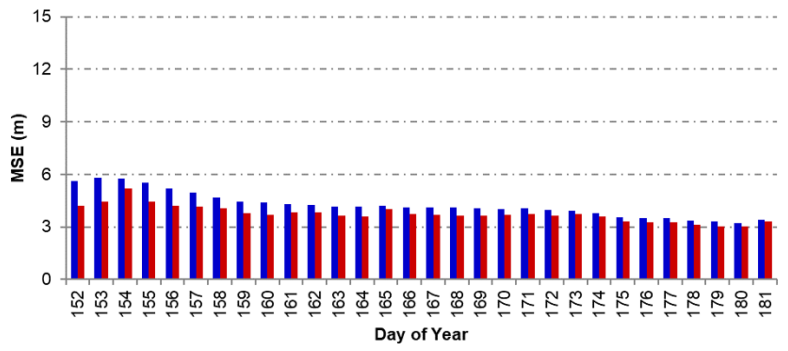

c)

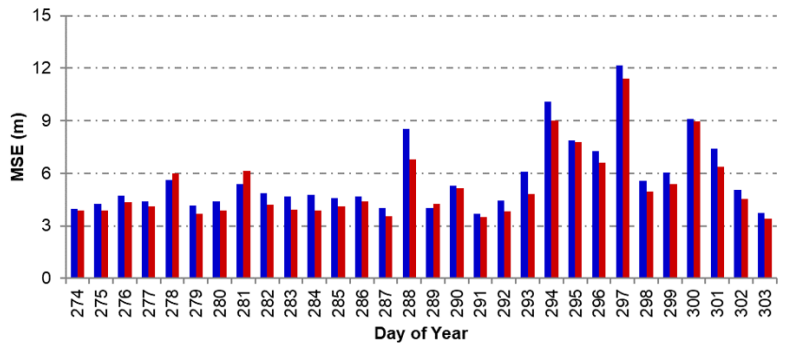

b)

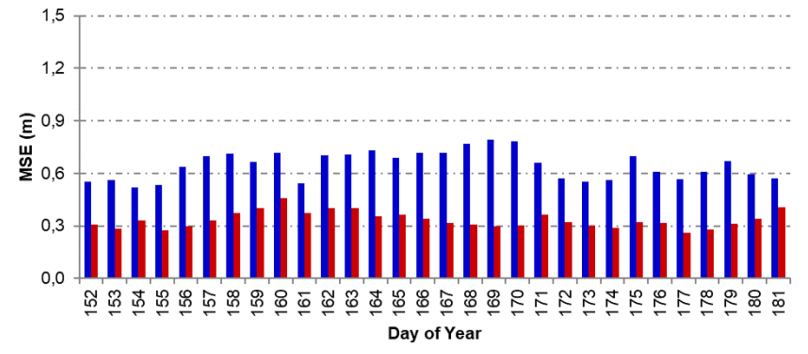

d)

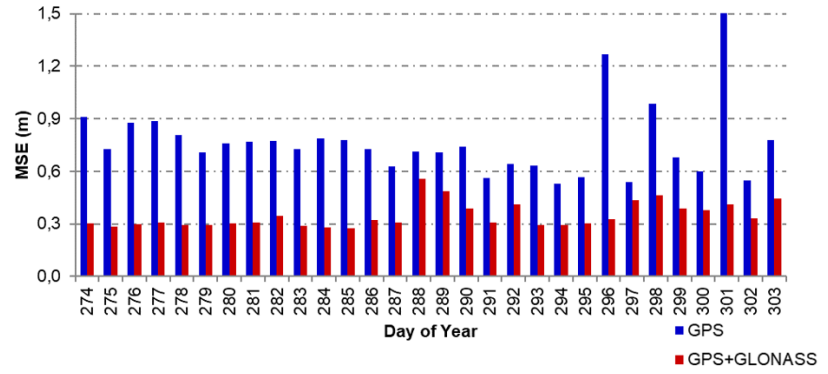

Figure 7: MSE results for PPP processing considering SCFL station with 30-minute data. a) L1 data collected in June;

b) L1/L2 data collected in for June; c) L1 data collected in for October; d) L1/L2 data collected in for October.

a)

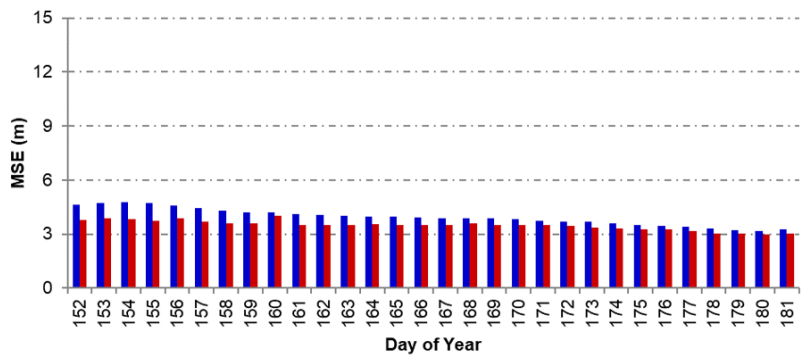

c)

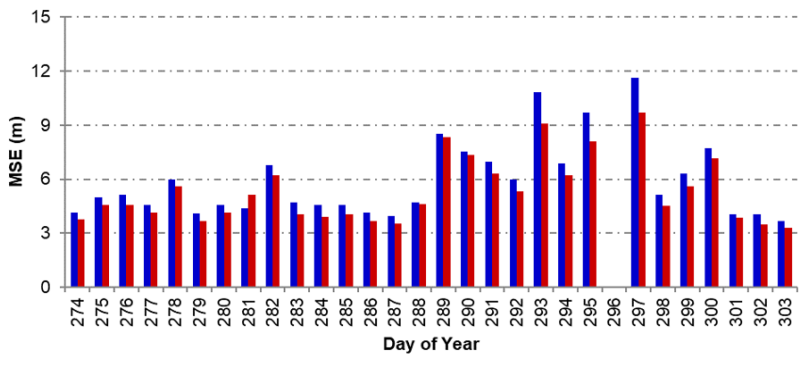

b)

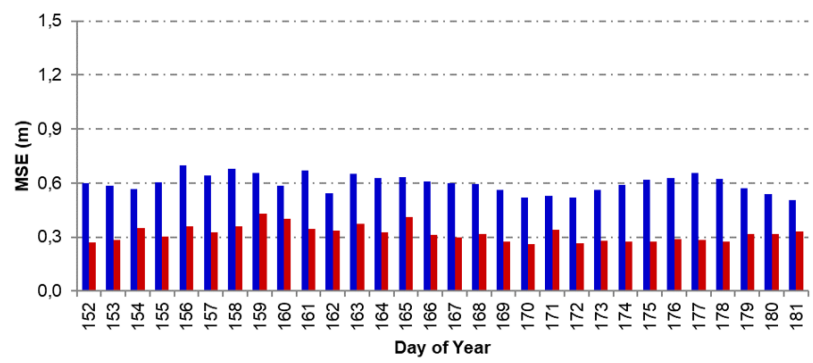

d)

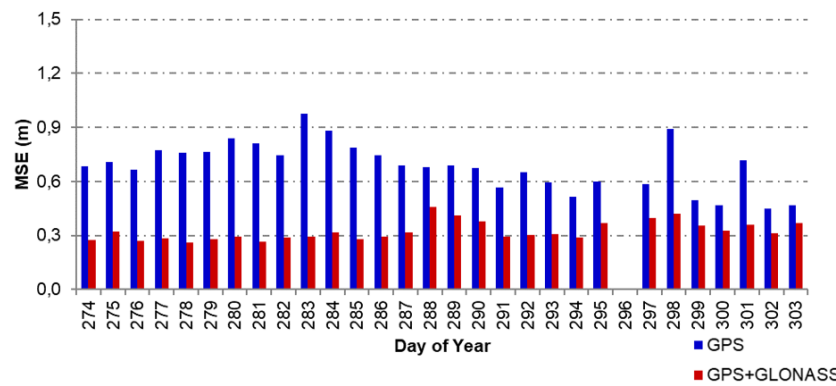

Figure 8: MSE results for PPP processing considering POAL station with 30-minute data. a) L1 data collected in June; b) L1/L2 data collected in for June; c) L1 data collected in for October; d) L1/L2 data collected in for October.

In order to summarize all information presented so far, Table 1 shows the MSE mean and standard deviations and percentages (minimum, mean and maximum values) of improvements obtained by using GPS/GLONASS data for each station. Only two configurations presented standard deviation higher than the mean value: stations PBJP and SCFL, both using L1 data from October (highlighted in grey). It was also noticed that the bigger improvements are observed in the period with higher ionospheric activity (October), the only exception are the values presented by SCFL station with L1 data, located in the region with lower ionospheric activity.

Considering the percentages of improvement by adding GLONASS to GPS data, Table 1 also presents MSE minimum, maximum and mean values for each station, for single and dual-frequency data with data from June and October. Negative values correspond to decrease in the positioning by adding GLONASS data. The minimum percentage of improvement was between a decrease of 16.8\% (POAL station with L1 data from October) and an improvement of 
44.3\% (PPTE station with $L 1+L 2$ data from June). The mean improvement values were between $8.05 \%$ (SCFL station with $\mathrm{L} 1$ data from October) and 59.62 (PPTE station with $\mathrm{L} 1+\mathrm{L} 2$ data from June). And the maximum percentages were between 16.36\% (POAL station with L1 data from October) and 80.06\% (PPTE station with L1+L2 data from June).

Table 2 presents MSE mean values and percentage of improvement obtained by using GPS/GLONASS considering all configurations for each station. It is possible to verify that the stations in the same regions presented an order of magnitude of the mean values and percentages of improvement similar, mainly the stations in the regions of fountain effect and with lower ionospheric activity. The PBJP station presented results closer to those from the fountain effect region, as previously mentioned, PBJP station is closer to $-15^{\circ}$ latitude than the CEFT station (closer to the Geomagnetic Equator) (as showed in Figure 1), which could explain the behavior of the results compared to those obtained with data from stations located in similar latitudes. Taking into account all configurations of all the stations, the use of GPS/GLONASS data provided better results in $97.35 \%$ of the cases, the mean improvement was about $60 \mathrm{~cm}$, which corresponds to $30 \%$. It is worthwhile to highlight that the improvement in the results of L1 data was higher than those of L1/L2 data, considering absolute values. Single frequency data presented a mean improvement of $75 \mathrm{~cm}$ by adding GLONASS data to GPS, against $45 \mathrm{~cm}$ when dual-frequency data are considered. As previously mentioned, single frequency data present higher error, thus higher improvement rates by using combined data were expected.

Table 1: MSE means and standard deviations and percentages (minimum, mean and maximum values) of the improvements obtained by using 30-minute GPS/GLONASS data.

\begin{tabular}{|c|c|c|c|c|c|c|c|}
\hline \multirow[b]{2}{*}{ Station } & \multirow[b]{2}{*}{ Data set } & \multirow[b]{2}{*}{ Month } & \multicolumn{5}{|c|}{ Improvement with GPS+GLONASS } \\
\hline & & & Mean $(\mathrm{m})$ & $\begin{array}{c}\text { Standard } \\
\text { Deviation }(\mathrm{m})\end{array}$ & Minimum (\%) & Mean (\%) & Maximum (\%) \\
\hline \multirow{4}{*}{ CEFT } & \multirow{2}{*}{ L1 } & June & 0.37 & 0.34 & -4.59 & 8.19 & 22.64 \\
\hline & & October & 0.76 & 0.48 & 3.00 & 11.47 & 22.73 \\
\hline & \multirow{2}{*}{$\mathrm{L} 1+\mathrm{L} 2$} & June & 0.21 & 0.08 & 19.43 & 38.56 & 51.01 \\
\hline & & October & 0.52 & 0.33 & 28.80 & 49.91 & 73.91 \\
\hline \multirow{4}{*}{ PBJP } & \multirow{2}{*}{ L1 } & June & 0.44 & 0.28 & 0.73 & 10.12 & 21.20 \\
\hline & & October & 1.44 & 1.60 & -6.73 & 14.70 & 43.93 \\
\hline & \multirow{2}{*}{$\mathrm{L} 1+\mathrm{L} 2$} & June & 0.28 & 0.13 & 22.09 & 44.94 & 66.03 \\
\hline & & October & 0.56 & 0.33 & 23.58 & 47.15 & 70.93 \\
\hline \multirow{4}{*}{ SPDR } & \multirow{2}{*}{ L1 } & June & 0.73 & 0.48 & 0.03 & 14.18 & 25.01 \\
\hline & & October & 1.26 & 1.02 & -4.80 & 13.64 & 32.51 \\
\hline & \multirow{2}{*}{$\mathrm{L} 1+\mathrm{L} 2$} & June & 0.46 & 0.18 & 43.91 & 58.22 & 72.64 \\
\hline & & October & 0.70 & 0.46 & 2.80 & 46.69 & 74.98 \\
\hline \multirow{4}{*}{ PPTE } & \multirow{2}{*}{ L1 } & June & 0.72 & 0.50 & -0.73 & 13.82 & 27.96 \\
\hline & & October & 1.28 & 1.26 & -6.54 & 14.64 & 57.43 \\
\hline & \multirow{2}{*}{ L1 } & June & 0.54 & 0.29 & 44.30 & 59.62 & 80.06 \\
\hline & & October & 0.73 & 0.51 & -4.65 & 48.49 & 78.50 \\
\hline \multirow{4}{*}{ SCFL } & \multirow{2}{*}{ L1 } & June & 0.49 & 0.34 & 2.91 & 10.86 & 25.19 \\
\hline & & October & 0.47 & 0.48 & -13.55 & 8.05 & 20.67 \\
\hline & \multirow{2}{*}{$\mathrm{L} 1+\mathrm{L} 2$} & June & 0.31 & 0.08 & 28.82 & 47.78 & 62.18 \\
\hline & & October & 0.43 & 0.25 & 19.43 & 52.12 & 77.59 \\
\hline \multirow{4}{*}{ POAL } & \multirow{2}{*}{ L1 } & June & 0.45 & 0.24 & 5.03 & 11.07 & 20.64 \\
\hline & & October & 0.56 & 0.49 & -16.90 & 9.06 & 16.36 \\
\hline & \multirow{2}{*}{$\mathrm{L} 1+\mathrm{L} 2$} & June & 0.28 & 0.05 & 31.54 & 46.46 & 56.74 \\
\hline & & October & 0.36 & 0.15 & 21.68 & 50.66 & 69.82 \\
\hline
\end{tabular}


Table 2: MSE mean improvement by using GPS/GLONASS data for each station.

\begin{tabular}{ccc}
\hline \multirow{2}{*}{ Station } & \multicolumn{2}{c}{ Improvement with GPS+GLONASS } \\
\cline { 2 - 3 } & Mean value $(\mathrm{m})$ & Mean percentage (\%) \\
\hline CEFT & 0.46 & 26.97 \\
\hline PBJP & 0.68 & 29.23 \\
\hline SPDR & 0.79 & 33.18 \\
\hline PPTE & 0.82 & 34.14 \\
\hline SCFL & 0.42 & 29.72 \\
\hline POAL & 0.41 & 29.30 \\
\hline
\end{tabular}

The high rate of days with improvement in the positioning by using GPS/GLONASS data can also be explained by the number of visible satellites. In order to investigate this issue, the last analysis performed in this data set compared the number of satellites available in the configurations used in the positioning processing. Considering all the stations in both periods, the minimum increase was of six satellites by adding the GLONASS constellation, the maximum was eleven satellites and a mean value of nine satellites increase was observed. Considering the mean number of GPS satellites available, the use of both constellations provided a mean increase of $70 \%$ in the number of satellites visible during the 30-minute collection time.

MSE values obtained with 04-hour data are also presented accordingly to the station considered. The first region is the nearest of Geomagnetic Equator, stations CEFT (Figure 9) and PBJP (Figure 10). Graphs follows the same pattern presented before: a) presents results of $L 1$ data and graph b) L1/L2 data, both from June; c) presents results of L1 data and graph d) L1/L2 data, both from October. The second region, represented by stations SPDR (Figure 11) and PPTE (Figure 12), is affected by the fountain effect. And the region with lower ionospheric activity is represented by stations SCFL (Figure 13) and POAL (Figure 14).

a)

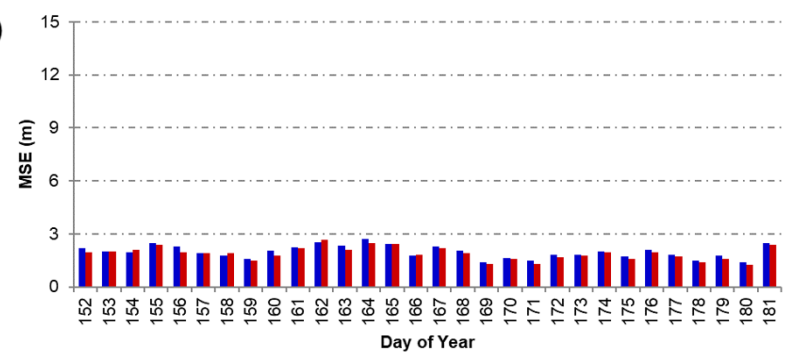

c)

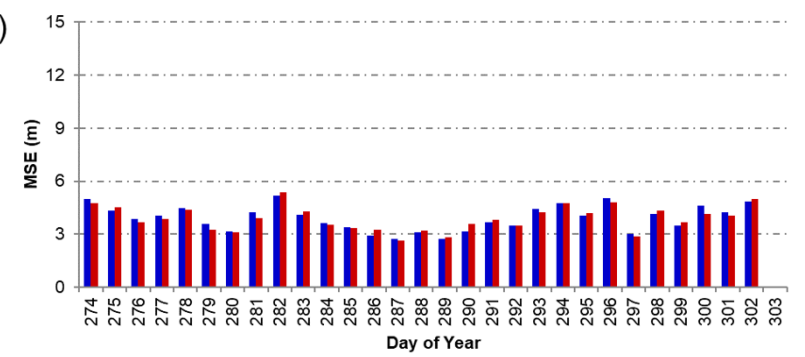

b)

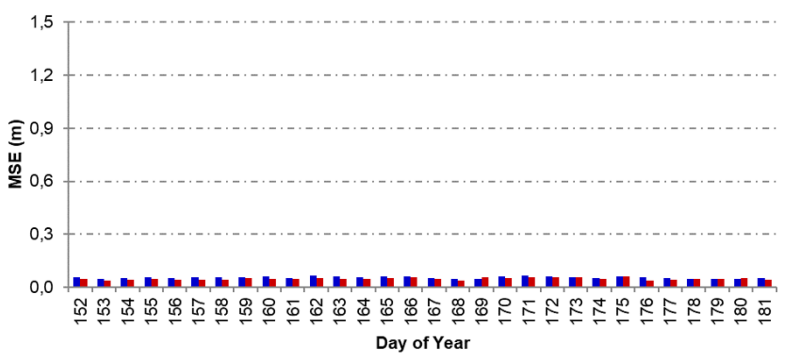

d)

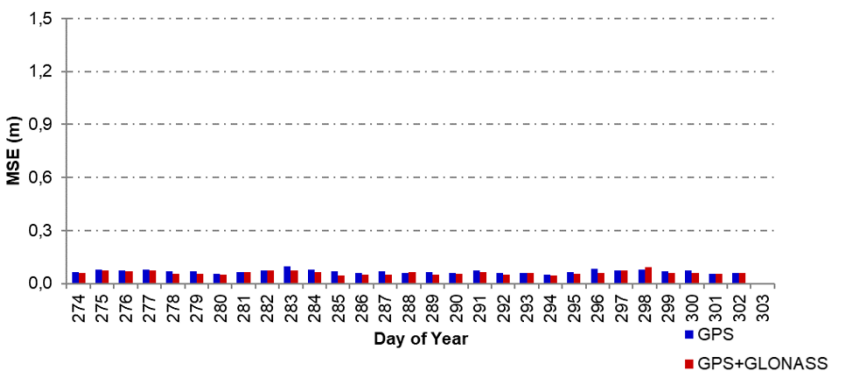

Figure 9: MSE results for PPP processing considering CEFT station with 04-hour data. a) L1 data collected in June; b) L1/L2 data collected in for June; c) L1 data collected in for October; d) L1/L2 data collected in for October. 
a)

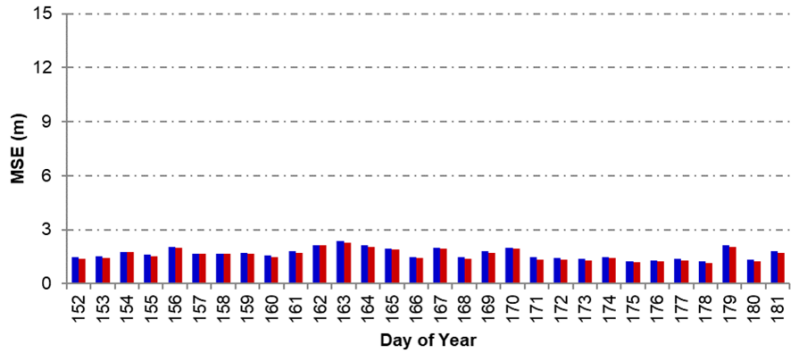

c)

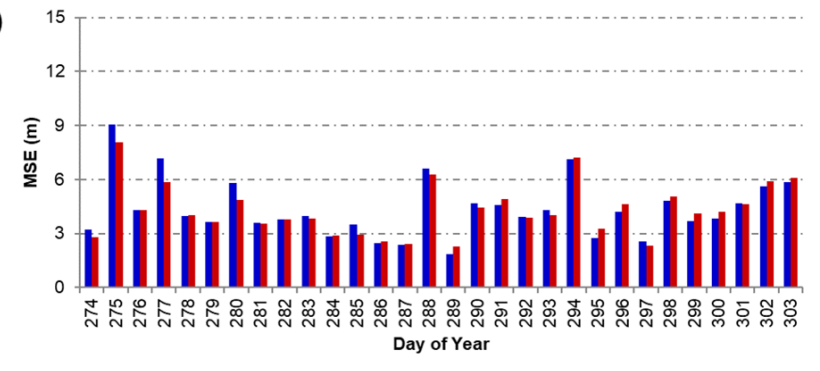

b)

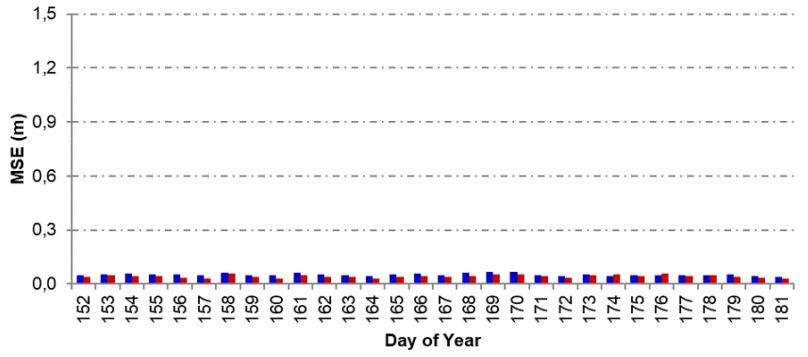

d)

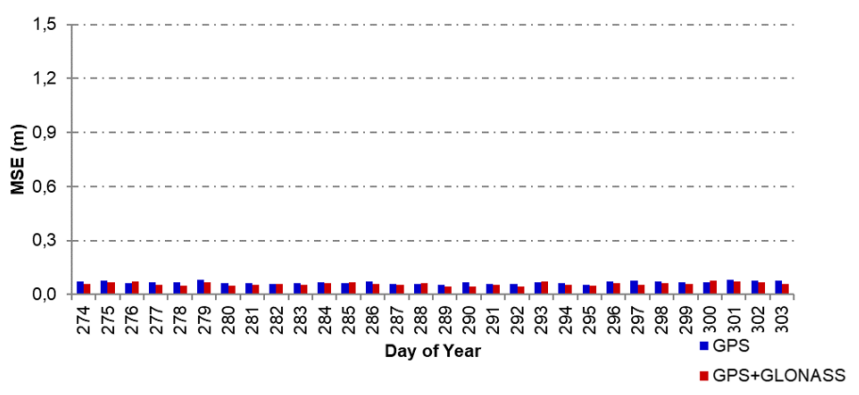

Figure 10: MSE results for PPP processing considering PBJP station with 04-hour data. a) L1 data collected in June; b) L1/L2 data collected in for June; c) L1 data collected in for October; d) L1/L2 data collected in for October.

a)

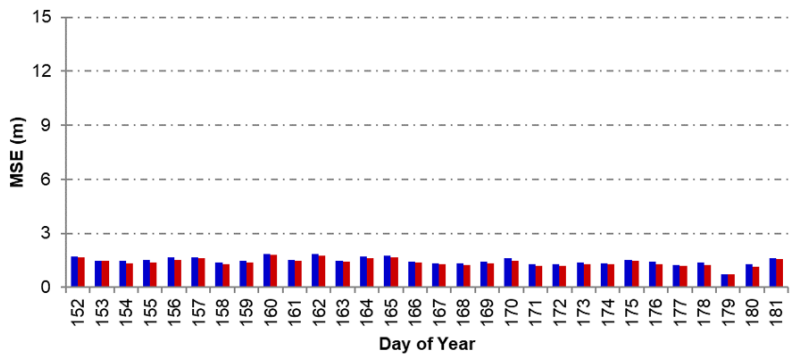

c)

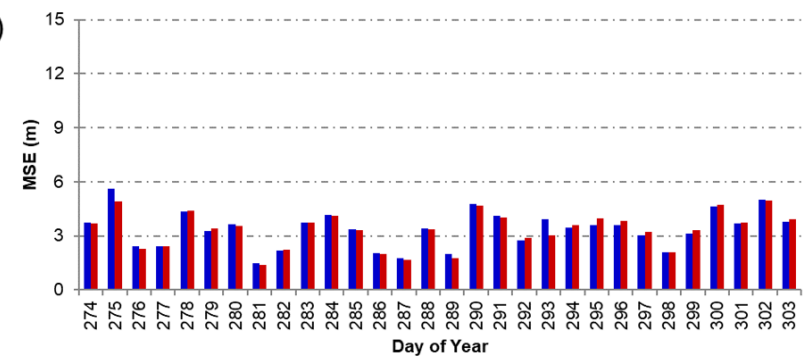

b)

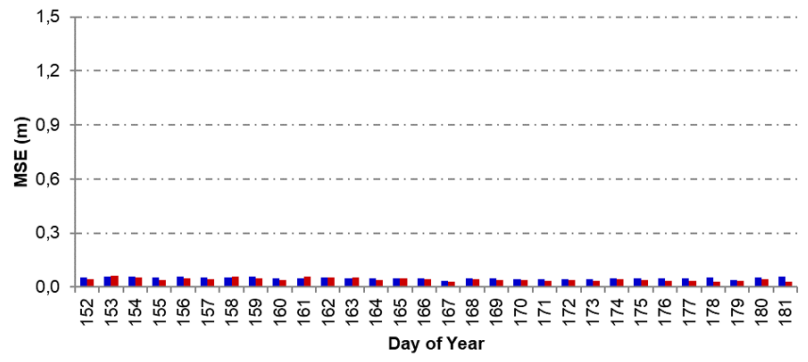

d)

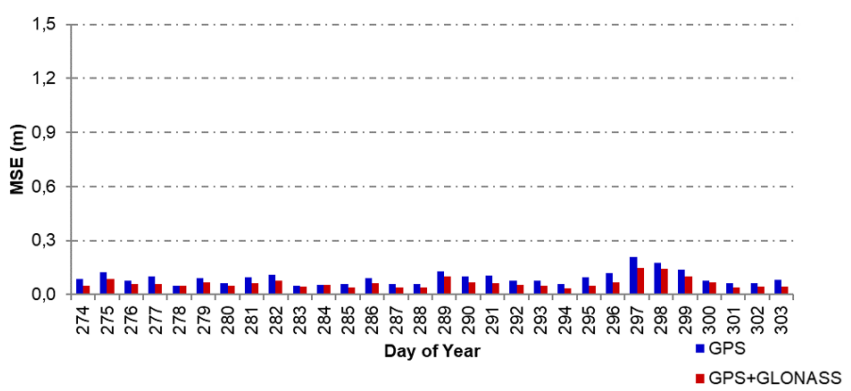

Figure 11: MSE results for PPP processing considering SPDR station with 04-hour data. a) L1 data collected in June; b) L1/L2 data collected in for June; c) L1 data collected in for October; d) L1/L2 data collected in for October.

Results of point positioning using 04-hour data presented more regular results with single or dual-frequency data for both periods (June and October). The influence of the use of single or dual-frequency data can still be noticed, with much smaller errors with dual-frequency. Besides the smaller values, the ionospheric influence on the results can still be noticed, mainly for single frequency data. The smaller errors were obtained at the stations in the region less affected by the ionosphere (SCFL and POAL) and considering data from June. 
a)

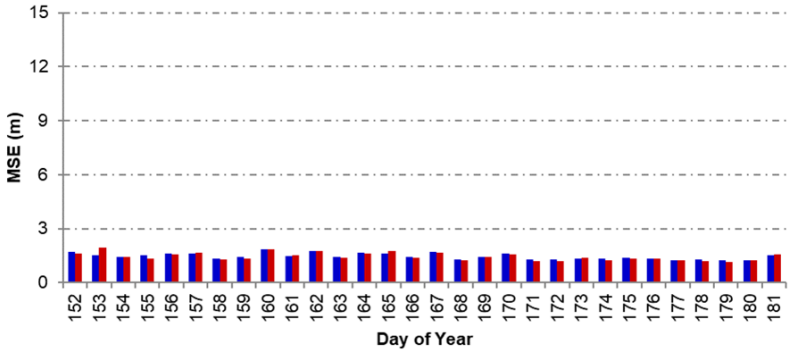

c)

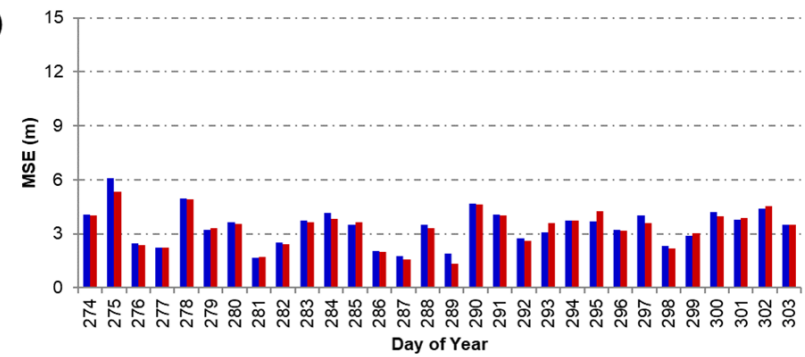

b)

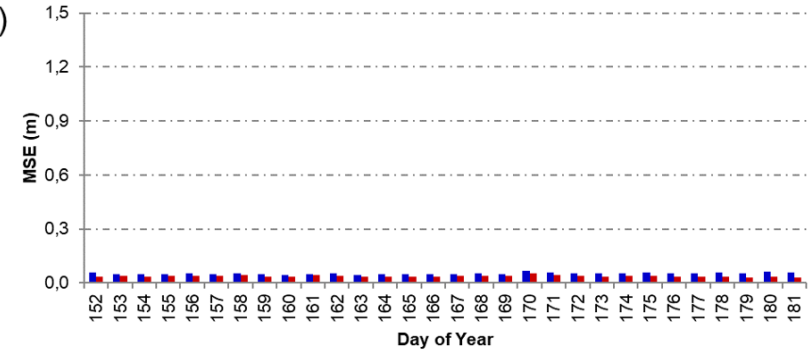

d)

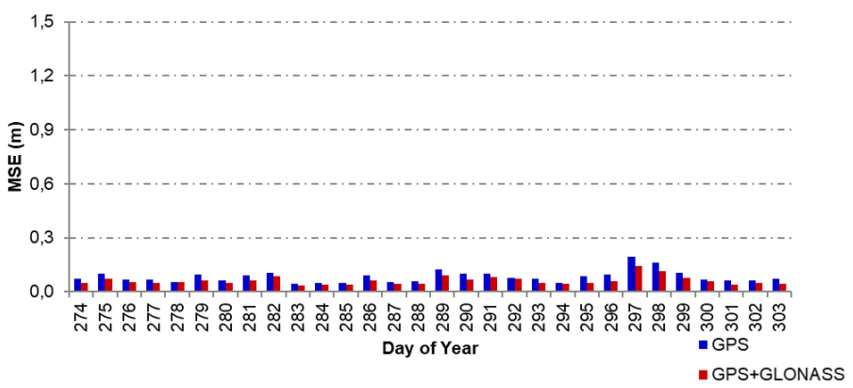

Figure 12: MSE results for PPP processing considering PPTE station with 04-hour data. a) L1 data collected in June; b) L1/L2 data collected in for June; c) L1 data collected in for October; d) L1/L2 data collected in for October.

a)

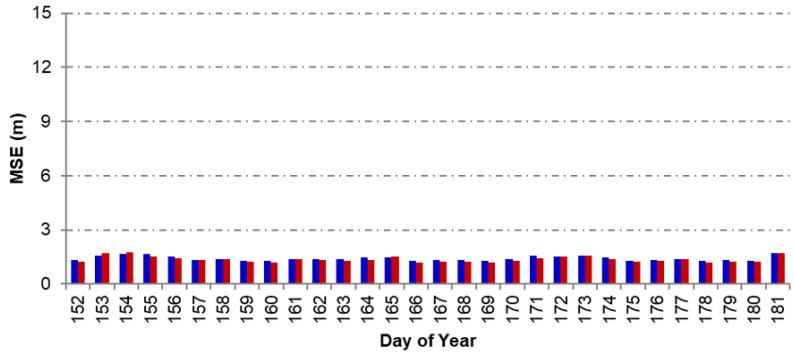

c)

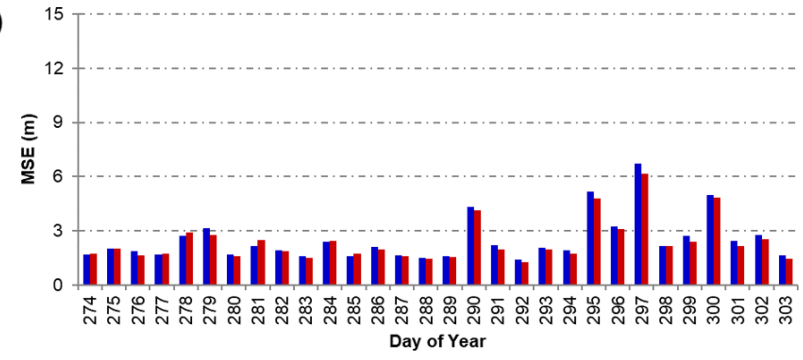

b)

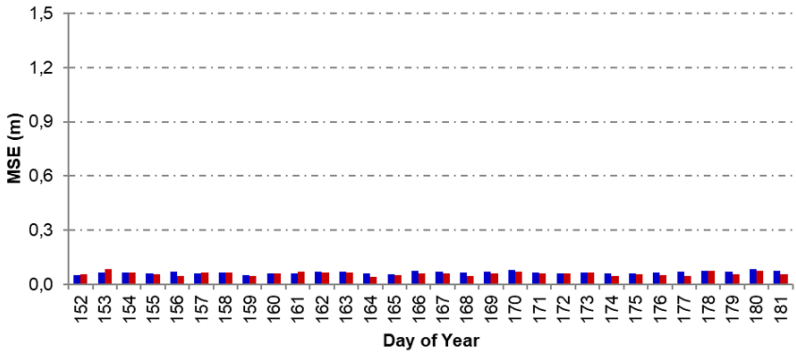

d)

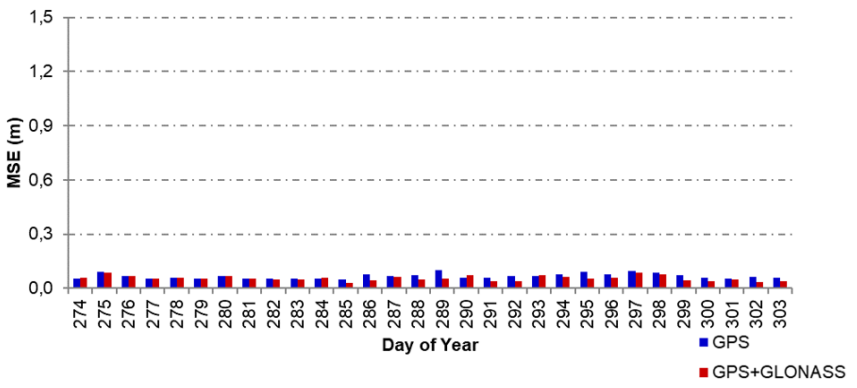

Figure 13: MSE results for PPP processing considering SFCL station with 04-hour data. a) L1 data collected in June; b) L1/L2 data collected in for June; c) L1 data collected in for October; d) L1/L2 data collected in for October.

In order to summarize the results from 04-hour data processing, Table 3 presents the mean and standard deviations of improvements obtained by using GPS/GLONASS data for all configurations. Even with more regular results, it is still possible to notice that L1 data from October (highlighted in grey) presented larger errors and variability (standard deviations). The station region seems to be less relevant for GNSS positioning when longer time of data collection is considered. Dual-frequency data presented better and similar results for all configurations analyzed. The behavior observed with 04-hour data can be explained by the amount of observable available, this way many errors are minimized and MSE obtained are more stable. 
a)

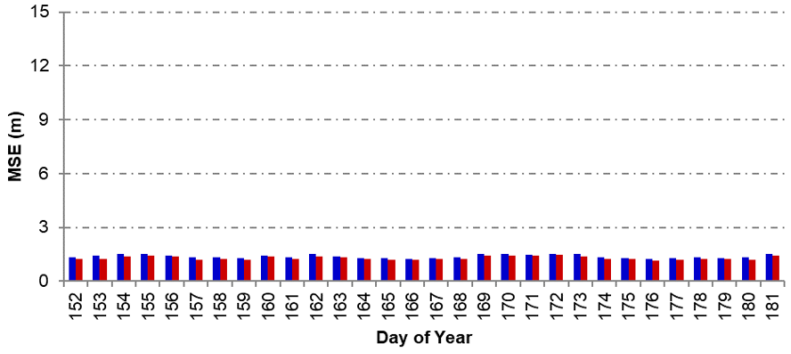

c)

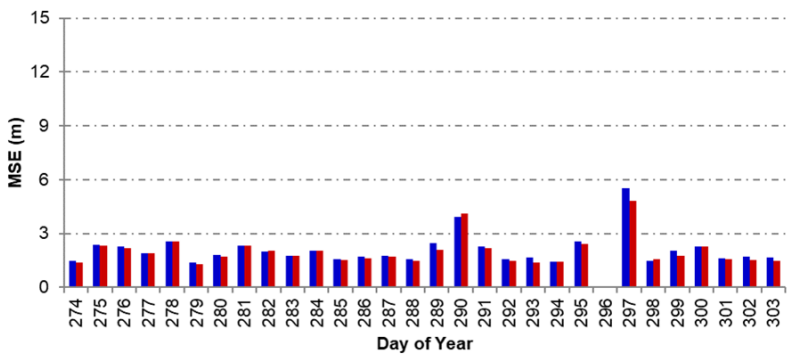

b)

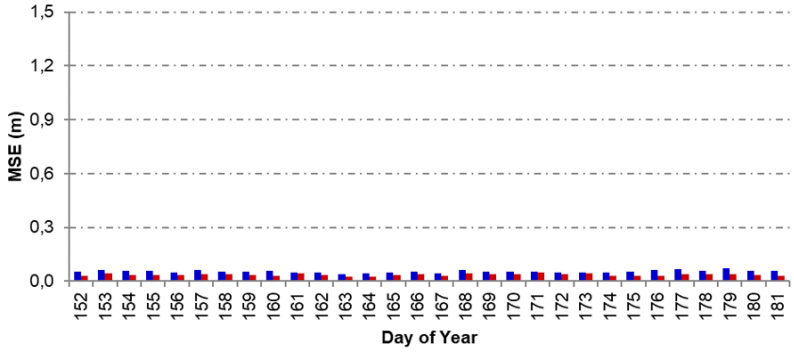

d)

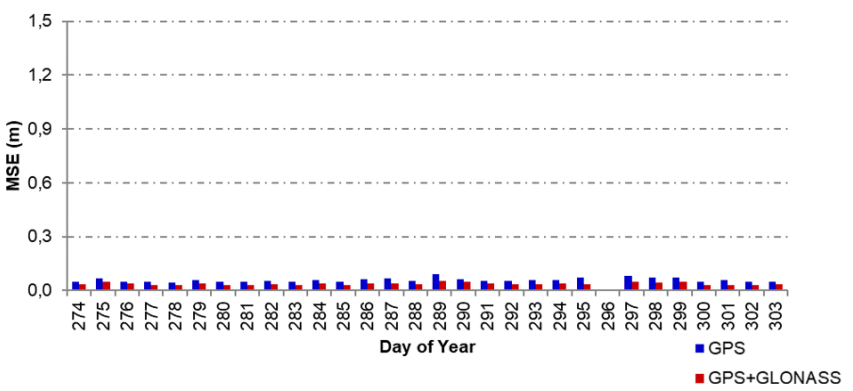

Figure 14: MSE results for PPP processing considering POAL station with 04-hour data. a) L1 data collected in June; b) L1/L2 data collected in for June; c) L1 data collected in for October; d) L1/L2 data collected in for October.

Results obtained in this paper were compatible with the ones with similar configurations previously quoted. Alkan et al. (2015) performed a study using the CSRS-PPP and magicGNSS/PPP softwares, with one-hour and dualfrequency data from a station in Turkey. Results obtained reached levels from decimeter to centimeter in some cases, with some stations presenting worse results by adding GLONASS data. It is important to highlight that the collection time used in the first data set of the present paper was 30 minutes, and that the region considered in the paper quoted presents lower ionospheric impact. Ventorim and Dal Poz (2016) also used CSRS-PPP for positioning, using IGS (International GNSS Service) stations, with 30-minute and 45-minute dual-frequency data. Accuracy obtained reached, in most part of the experiment, a decimeter to centimeter level, with some cases (with GPS-only or GLONASS-only processing) presenting metric discrepancies. The authors indicated the influence of the collection time, with significant improvements with the results with 45 minutes, when compared with 30-minute data. The multiconstellation study performed by Cai et al. (2015) used the MIPS-PPP (multi-GNSS integrated positioning software for PPP). Five stations from China, Australia and Japan were used, considering the three-hour collection time and dual-frequency data. GPS and GPS/GLONASS reached mean RMS at centimeter level, with the biggest improvement in the time of convergency, by adding GLONASS data. Cai and Gao (2013a; 2013b) presented assessment approaches to GLONASS and GPS/GLONASS PPP, with three-hour and 24-hour data. The authors also used IGS stations and dualfrequency data. Convergence time was evaluated, with RMS final values with centimeter level. Higher values are observed in the first hour of processing, with some components (east, north or up) reaching metric level. Silva and Marques (2016) also used the CSRS-PPP to perform a study using Brazilian stations, considering dual-frequency and 24-hour data. Mean RMS considering one year (2013) was from around 1-2 cm, for the five stations.

Additional results of CEFT, PPTE and POAL stations, presented in a local geodetic system, can be found in Jerez (2017). Other assessment approaches using multivariate analysis techniques in this study are presented in Jerez, Alves and Tachibana (2019). In Jerez and Alves (2019), the point positioning was also applied, but to assess the performance of GPS and GLONASS virtual data, generated in positions considering different ionospheric conditions in the Brazilian region. 
Table 3: MSE mean and standard deviation values of improvements by using 04-hour GPS/GLONASS data.

\begin{tabular}{|c|c|c|c|c|}
\hline \multirow{2}{*}{ Station } & \multirow{2}{*}{ Data set } & \multirow{2}{*}{ Month } & \multicolumn{2}{|c|}{ Improvement with GPS+GLONASS } \\
\hline & & & Mean (m) & Standard Deviation $(\mathrm{m})$ \\
\hline \multirow{4}{*}{ CEFT } & \multirow{2}{*}{$\mathrm{L} 1$} & June & 0.09 & 0.11 \\
\hline & & October & 0.01 & 0.21 \\
\hline & \multirow{2}{*}{$\mathrm{L} 1+\mathrm{L} 2$} & June & 0.01 & 0.01 \\
\hline & & October & 0.01 & 0.01 \\
\hline \multirow{4}{*}{ PBJP } & \multirow{2}{*}{ L1 } & June & 0.07 & 0.03 \\
\hline & & October & 0.07 & 0.44 \\
\hline & \multirow{2}{*}{$\mathrm{L} 1+\mathrm{L} 2$} & June & 0.01 & 0.01 \\
\hline & & October & 0.01 & 0.01 \\
\hline \multirow{4}{*}{ SPDR } & \multirow{2}{*}{ L1 } & June & 0.09 & 0.04 \\
\hline & & October & 0.03 & 0.25 \\
\hline & \multirow{2}{*}{$\mathrm{L} 1+\mathrm{L} 2$} & June & 0.01 & 0.01 \\
\hline & & October & 0.03 & 0.01 \\
\hline \multirow{4}{*}{ PPTE } & \multirow{2}{*}{ L1 } & June & 0.02 & 0.10 \\
\hline & & October & 0.07 & 0.26 \\
\hline & \multirow{2}{*}{ L1 } & June & 0.01 & 0.01 \\
\hline & & October & 0.02 & 0.01 \\
\hline \multirow{4}{*}{ SCFL } & \multirow{2}{*}{ L1 } & June & 0.05 & 0.07 \\
\hline & & October & 0.12 & 0.18 \\
\hline & \multirow{2}{*}{$\mathrm{L} 1+\mathrm{L} 2$} & June & 0.01 & 0.01 \\
\hline & & October & 0.01 & 0.01 \\
\hline \multirow{4}{*}{ POAL } & \multirow{2}{*}{$\mathrm{L} 1$} & June & 0.08 & 0.03 \\
\hline & & October & 0.10 & 0.16 \\
\hline & \multirow{2}{*}{$\mathrm{L} 1+\mathrm{L} 2$} & June & 0.02 & 0.01 \\
\hline & & October & 0.02 & 0.01 \\
\hline
\end{tabular}

\section{Conclusions}

This paper aimed to assess the performance of GPS/GLONASS data for point positioning in Brazilian regions under different ionospheric influence considering periods of low and high ionospheric activity. For this purpose, we used data of six GNSS stations of RBMC from June and October 2014.

The results have indicated the ionospheric influence in the GNSS positioning error considering both, spatial and time relation. The highest and most irregular errors in the positioning were those from October data, mainly in the region affected by the fountain effect. The lowest and more regular results were obtained with data of stations located in a region with low ionospheric activity. It was also noticed the differences in the positioning performance by using single or dual-frequency data.

Adding GLONASS to GPS data improved the positioning results in most part of the cases, mainly when smaller collection times were considered. Considering all configurations tested for all the stations with 30-minute data, the use of GPS/GLONASS data provided better results in $97.35 \%$ of the cases, the mean improvement was about $60 \mathrm{~cm}$ (30\% improvement). The mean increase in the number of satellites visible with combined data was nine vehicles, which corresponds to a $70 \%$ improvement. 


\section{ACKNOWLEDGEMENT}

This study was financed in part by the Coordenação de Aperfeiçoamento de Pessoal de Nível Superior - Brasil (CAPES) - Finance Code 001.

\section{AUTHOR'S CONTRIBUTION}

Both authors conceived the ideas; Jerez, G. O. performed the experiments and wrote the manuscript; Both authors contributed to the analysis and discussions of the results and participated in the editing of this paper.

\section{REFERENCES}

Alkan, R. M., Ilçi, V., Ozulu, I. M., Saka, M. H. 2015. A comparative study for accuracy assessment of PPP technique using GPS and GLONASS. Measurements, 69, pp. 1-8.

Cai, C., Gao, Y. 2013a. GLONASS-based precise point positioning and performance analysis. Advances in Space Research, 51(3), pp. 514-524.

Cai, C., Gao, Y. 2013b. Modeling and assessment of combined GPS/GLONASS precise point positioning. GPS Solutions, 17(2), pp. 223-236.

Cai, C., Gao, Y., Pan, L., Zhu, J. 2015. Precise point positioning with quad-constellations: GPS, BeiDou, GLONASS and Galileo. Advances in Space Research, 56(1), pp. 133-143.

Conker, R.S., El-Arini, M.B., Hegarty, C.J., Hsiao, T., 2003. Modeling the effects of ionospheric scintillation on GPS/ Satellite-Based augmentation system Availability. Radio Science, 38 (1), pp.1-23.

de Rezende, L. F. C, de Paula, E. R., Kantor, I. J., Kintner, P. M. 2007. Mapping and survey of plasma bubbles over Brazilian territory. The Journal of Navigation, 60, pp. 69-81.

Feairheller, S., Clark, R., 2006. Other satellite navigation systems. In: Kaplan, E.D., Hegarty, C.J. (Eds.), Understanding GPS: Principles and Applications, 2 ed. Artech House, Norwood, pp. 595-634.

Geng, J., Shi, C. 2017. Rapid initialization of real-time PPP by resolving undifferenced GPS and GLONASS ambiguities simultaneously. Journal of Geodesy, 91(4), pp. 361-374.

Hofmann-Wellenhof, B. Lichtenegger, H. Wasle, E. 2008. GNSS - Global Navigation Satellite Systems GPS, GLONASS, Galileo, and more. New York: Springer-Verlag.

Jerez, G. O. 2017. Análise da integração GPS/GLONASS para posicionamento sob efeito de cintilação ionosférica. Master. Universidade Estadual Paulista.

Jerez, G. O., Alves, D. B. M., Souza, J. S. 2015. Análise do uso combinado GPS/GLONASS no posicionamento sob efeito de cintilação ionosférica. Revista Brasileira de Cartografia, 67(1), pp. 201-214.

Jerez, G. O., Alves, D. B. M. 2019. Generation and performance analysis of GPS and GLONASS virtual data for positioning under different ionospheric conditions. Boletim de Ciências Geodésicas, 25(2), pp. 1-17.

Jerez, G. O., Alves, D. B. M., Tachibana, V. M. 2019. Multivariate analysis of combined GPS/GLONASS point positioning performance in Brazilian regions under different ionospheric conditions. Journal of Atmospheric and Solar-Terrestrial Physics, 187, pp. 1-9. 
Klobuchar, J.A., 1996. Ionospheric effects on GPS. In: In: Parkinson, B.W., Spilker, J.J. (Eds.), Global Positioning System: Theory and Applications, vol. I. American Institute of Aeronautics and Astronautics, Washington, DC, pp. 485-515.

Langley, R. B., Teunissen, P. J. G., Montenbruck, O. 2017. Introduction to GNSS. In: Teunissen, P., Montenbruck, O., eds. 2017. Springer Handbook of Global Navigation Satellite Systems. Springer: Cham, pp. 3-23.

Li, P., Zhang, X. 2014. Integrating GPS and GLONASS to accelerate convergence and initialization times of precise point positioning. GPS Solutions, 18(3), pp. 461-471.

McNamara, L. F. 1991. The ionosphere: communications, surveillance, and direction finding. Florida: Krieger Publishing Company.

Moraes, A. O., Vani, B. C., Costa, E., Abdu, M. A, de Paula, E. R., Santos, J. S., Monico, J. F. G., Forte, B., Negreti, P. M. S., Shimabukuro, M. H. 2018. GPS Availability and Positioning issues when the signal paths are aligned with ionospheric bubbles. GPS Solutions, 22(4), pp. 95-106.

Pinto, M. S., Camargo, P. O., Monico, J. F. G. 2013. Influência da combinação de dados GPS e GLONASS no georreferenciamento de imóveis rurais. Boletim de Ciências Geodésicas, 19(1), pp. 135-151.

Revnivykh, S. Bolkunov, A. Serdyukov, A. and Montenbruck, O. 2017. GLONASS. In: Teunissen, P., Montenbruck, O. (Eds). Springer Handbook of Global Navigation Satellite Systems. Springer, Cham, pp. 219-245.

Silva, E. G. S., Marques, H. A. 2016. PPP com integração de dados GPS/GLONASS: fundamentos envolvidos e análise de acurácia. Boletim de Ciências Geodésicas, 22(2), pp. 217-231.

Ventorim, B. G., Dal Poz, W. R. 2016. Avaliação do desempenho dos sistemas GPS e GLONASS no posicionamento por ponto preciso, combinados e individualmente. Boletim de Ciências Geodésicas, 22(2), pp. 265-281. 